\title{
Nonlinear forcing mechanisms of the migrating terdiurnal solar tide and their impact on the zonal mean circulation
}

\author{
Friederike Lilienthal and Christoph Jacobi \\ Institute for Meteorology, Universität Leipzig, Stephanstr. 3, 04103 Leipzig, Germany \\ Correspondence: Friederike Lilienthal (friederike.lilienthal@uni-leipzig.de)
}

Received: 8 March 2019 - Discussion started: 1 April 2019

Revised: 13 August 2019 - Accepted: 5 September 2019 - Published: 10 October 2019

\begin{abstract}
We investigate the forcing mechanisms of the terdiurnal solar tide in the middle atmosphere using a mechanistic global circulation model. In order to quantify their individual contributions, we perform several model experiments and separate each forcing mechanism by switching off the remaining sources. We find that the primary excitation is owing to the terdiurnal component of solar radiation absorption in the troposphere and stratosphere. Secondary sources are nonlinear tide-tide interactions and gravity wave-tide interactions. Thus, although the solar heating clearly dominates the terdiurnal forcing in our simulations, we find that nonlinear tidal and gravity wave interactions contribute in certain seasons and at certain altitudes. By slightly enhancing the different excitation sources, we test the sensitivity of the background circulation to these changes of the dynamics. As a result, the increase of terdiurnal gravity wave drag can strongly affect the middle and upper atmosphere dynamics, including an irregular change of the terdiurnal amplitude, a weakening of neutral winds in the thermosphere, and a significant temperature change in the thermosphere, depending on the strength of the forcing. On the contrary, the influence of nonlinear tidal interactions on the middle atmosphere background dynamics is rather small.
\end{abstract}

\section{Introduction}

The middle atmosphere dynamics are mainly determined by waves that are excited in the troposphere or stratosphere and propagate to the upper atmosphere (see, e.g., reviews by Forbes, 1995; Yiğit and Medvedev, 2015). These waves can be either global scale, like atmospheric solar tides, or small scale, like the internal gravity waves (GWs). GWs are generated in the lower atmosphere due to geography, convective instabilities, wind shears, jet streams, spontaneous adjustment, or wave-wave interactions (Fritts and Alexander, 2003). Due to wave breaking and momentum deposition they are mainly responsible for the wind reversal in the mesosphere and lower thermosphere (MLT) region. However, GWs also play an important role in the thermosphere where they can damp or enhance tides (e.g., Yiğit et al., 2008; Yiğit and Medvedev, 2017), and may also transport wave signatures to the thermosphere (e.g., Eckermann et al., 1997; Meyer, 1999; Hoffmann et al., 2012).

Atmospheric solar tides are global-scale waves owing to the diurnal variation of solar radiation. Therefore, they have periods of a solar day and its harmonics. They are primarily excited in the water vapor and ozone heating region (Chapman and Lindzen, 1970; Andrews et al., 1987). Due to decreasing density with increasing height, tides reveal their maximum amplitudes in the MLT region. Above, in the thermosphere, they are damped, e.g., by increasing molecular diffusion and thermal conduction. Tides modulate the background wind field and, therefore, have an impact on the propagation conditions of GWs (e.g., Eckermann and Marks, 1996; Senf and Achatz, 2011; Yiğit and Medvedev, 2017; Baumgarten et al., 2018).

Amplitudes of diurnal tides (DTs) and semidiurnal tides (SDTs) are generally larger than those related to higher harmonics and wave numbers such as the terdiurnal tide (TDT). However, during some seasons the TDT amplitudes may locally become comparable to those of the DT (Cevolani and Bonelli, 1985; Reddi et al., 1993; Thayaparan, 1997; Younger et al., 2002). For example, radar measurements at midlatitudes show large TDT amplitudes in autumn and early winter (Beldon et al., 2006; Jacobi and Fytterer, 2012; 
Jacobi, 2012), and also in spring (Thayaparan, 1997). Global observations of the TDT have been presented by Smith (2000), Moudden and Forbes (2013), Pancheva et al. (2013), and Yue et al. (2013). Yue et al. (2013) obtained TDT amplitudes of more than $16 \mathrm{~m} \mathrm{~s}^{-1}$ at $50^{\circ} \mathrm{N} / \mathrm{S}$ above $100 \mathrm{~km}$ from observations using the Thermosphere Ionosphere Mesosphere Energetics and Dynamics Doppler Interferometer (TIMED/TIDI). They reported another maximum in the meridional wind at about $82 \mathrm{~km}$ at lower northern latitudes. For an altitude of $90 \mathrm{~km}$, based on Sounding of the Atmosphere using Broadband Emission Radiometry (SABER) data, Moudden and Forbes (2013) observed large amplitudes over the Equator during equinoxes $(6-8 \mathrm{~K})$, and also at $60^{\circ}$ during spring.

While the excitation mechanism is relatively well known for the DT and SDT, those of the TDT are still under debate (e.g., Lilienthal et al., 2018, and references therein). Besides the direct solar forcing, higher harmonics are also subject to nonlinear tidal interaction (e.g., Glass and Fellous, 1975; Teitelbaum et al., 1989; Teitelbaum and Vial, 1991). For example, the interaction between DT and SDT can lead to a secondary TDT. Additionally, interactions between GWs and tides can also produce a secondary TDT (Miyahara and Forbes, 1991). Ribstein and Achatz (2016) have shown that such interactions strongly depend on model physics but they did not include the TDT in their analysis.

The excitation mechanisms of the TDT have been investigated by several model studies (Akmaev, 2001; Smith and Ortland, 2001; Huang et al., 2007; Du and Ward, 2010; Lilienthal et al., 2018) but with partly inconclusive results. This is most likely caused by different models and analysis techniques, e.g., Akmaev (2001) and Smith and Ortland (2001) use models with explicit lower boundary forcing of DT and SDT whereas the simulations of Du and Ward (2010) and Lilienthal et al. (2018) are based on fully self-consistent tides. Furthermore, the authors partly focused on different latitudes and altitudes that cannot be easily compared.

The majority of these publications agrees that the direct solar forcing is the most dominant, although not the only, excitation mechanism of the TDT (Akmaev, 2001; Smith and Ortland, 2001; Du and Ward, 2010; Lilienthal et al., 2018). For example, Huang et al. (2007) found significant nonlinear TDT amplitudes above $90 \mathrm{~km}$, especially during equinoxes, which agrees with the simulations by Akmaev (2001). Lilienthal et al. (2018) found that the solar forcing is the primary excitation mechanism, but nonlinear tide-tide interactions and also GW-tide interactions play a role. They analyzed the phase relations of differently forced TDTs and found destructive interferences between them. This suggests that different excitation mechanisms can also counteract each other, partly leading to a reduced and not an enhanced TDT.

To extend the work of Lilienthal et al. (2018) and in order to further investigate the nonlinear mechanisms of TDT forcing, we now present model simulations, which are each restricted to only one terdiurnal forcing mechanism, i.e., ei- ther the solar heating absorption, or nonlinear tidal interactions, or GW-tide interactions. The remainder of this paper is organized as follows. In Sect. 2, the model and experimental setup is described, and in Sect. 3 the results of the model runs are discussed with respect to TDT zonal wind amplitudes (Sect. 3.1). In Sect. 3.2 a sensitivity study with modified forcings is presented and the effect of the modified forcings on the mean flow is analyzed. Section 4 concludes the paper.

\section{Model description and experimental setup}

In the following analysis we use the Middle and Upper Atmosphere Model (MUAM) in the same configuration as described in detail by Lilienthal et al. (2017, 2018). In short, MUAM is a mechanistic primitive equation global circulation model that reaches from the troposphere to the thermosphere, i.e., to about $160 \mathrm{~km}$ in logarithmic-pressure height, given a constant scale height of $7 \mathrm{~km}$. The horizontal resolution is $5^{\circ} \times 5.625^{\circ}$ in latitude and longitude. The model's zonal mean temperature in the troposphere and lower stratosphere is nudged by monthly mean zonal mean ERA-Interim reanalysis (ERA-Interim, 2018; Dee et al., 2011) temperatures. To provide ensemble simulations for each of the following experiments, 11 ensemble members are driven by monthly mean ERA-Interim reanalysis of the years 2000 to 2010. In this way, a set of ensembles also represents some kind of interannual variability, as shown by Lilienthal et al. (2018).

There are three main sources of atmospheric tides in the model. The primary source is the absorption of solar radiation which creates tides in a self-consistent manner. The solar heating is parameterized according to Strobel (1978) and considers heating due to all important gases for tidal forcing such as water vapor and ozone in the troposphere and stratosphere, as well as oxygen and nitrogen in the thermosphere. For more details, see Lilienthal et al. (2018).

Nonlinear interactions between different tides and between GWs and tides can generate a secondary TDT as described in Sect. 1. The interactions related to GWs can be realized within the GW parameterization of the model. This is a coupled parameterization based on an updated linear scheme for the lower and middle atmosphere (Lindzen, 1981; Jakobs et al., 1986; Fröhlich et al., 2003; Jacobi et al., 2006) and an adjusted nonlinear scheme according to Yiğit et al. (2008, 2009), see also Lilienthal et al. (2017, 2018), for the thermosphere. Even though both schemes are coupled through the eddy diffusion coefficient, which is transferred from the linear scheme to the nonlinear scheme, both parameterizations are almost independent of each other, because they handle a different range of phase speeds without overlap, i.e., the linear scheme is responsible for slowly traveling GWs that mainly break in the middle atmosphere while the nonlinear 
scheme is responsible for fast traveling GWs that reach the lower thermosphere.

Nonlinear interactions are a rather dynamic feature of the tendency equations of the model. They are, mathematically, to a certain degree hidden in the product of non-zonal parameters of the model equations. In particular, they are included in the advection terms and in the adiabatic heating component (see also Lilienthal et al., 2018). Further interactions, i.e., further products of non-zonal parameters, are possible within the parameterizations of eddy diffusion, molecular conduction, and in the Coriolis terms. However, these terms are comparatively small and their separation and extraction partly leads to numerical instabilities. Therefore, these terms are neglected in the following. To summarize, the main three forcing mechanisms of TDTs in MUAM are the direct solar forcing, nonlinear tidal interactions, and GW-tide interactions.

In order to quantify the relevance of these three mechanisms, Lilienthal et al. (2018) performed model runs; each of these runs involved removing one of the three mechanisms in order to determine the change in tidal amplitude due to this forcing. Following Lilienthal et al. (2018) and extending the analysis, we now do the opposite and remove all forcing mechanisms except for the respective mechanism of interest. The procedure to remove the nonlinear terms is technically the same as that used by Lilienthal et al. (2018). A fast Fourier transform according to Danielson and Lanczos (1942) is used to extract the wave number 3 pattern in each time step of the model. Due to the fact that the model, in the current configuration, does not generate nonmigrating tides, this is the simplest way to remove the whole TDT structure. In contrast to Lilienthal et al. (2018), this is not only applied to one of the forcing terms, but to two of them in parallel. The remaining amplitudes can be directly attributed to the respective third and remaining forcing. Thereby we produce a reference simulation with all forcing mechanisms included, and three further simulations:

- REF: reference run - this is the same simulation as that shown by Lilienthal et al. (2018);

- SOL: no nonlinear and GW forcing - TDT amplitudes are only owing to the absorption of solar radiation;

- NLIN: no solar and GW forcing - TDT amplitudes are only owing to nonlinear tidal interactions;

- GWF: no solar and nonlinear forcing - TDT amplitudes are only owing to GW-tide interactions.

All of these simulations are performed as ensembles as described above.

In order to investigate the impact of these forcing mechanisms on the background circulation, we also enhance the respective remaining forcing in the SOL, NLIN, and GWF simulations, stepwise. Therefore, each simulation represents a certain factor of enhancement. Technically, this is the same procedure as that for the removal of terdiurnal forcing terms, except that the respective wave number 3 forcing is increased by a certain factor. In order to reduce the computation time for the simulations with enhanced forcing mechanisms, only the $5 \%$ enhanced runs (NL5 and GW5) are performed as ensembles, while different enhancements are only performed for the year 2000 .

\section{Results}

\subsection{Zonal wind amplitude distributions for different forcing mechanisms}

Lilienthal et al. (2018) have shown that, in accordance with ground-based and satellite measurements (e.g., Teitelbaum et al., 1989; Thayaparan, 1997; Jacobi, 2012; Guharay et al., 2013; Yue et al., 2013), TDT amplitudes in MUAM maximize during autumn and winter at midlatitudes and during equinoxes near the Equator (see also Fig. S1 in the Supplement). Therefore, we focus on January conditions in the following, while additional figures for April, July, and October can be found in the Supplement.

We present the latitudinal and vertical structure of the TDT for different forcing mechanisms (Fig. 1), i.e., for the REF (panel a), SOL (panel b), NLIN (panel c), and GWF (panel d) simulations. Note that the amplitudes of the REF simulation are generally smaller than those observed. This is due to the fact that MUAM tends to underestimate tides in general, which is frequently also seen in other models (Smith, 2012; Pokhotelov et al., 2018; Lilienthal et al., 2018). The standard deviations, however, are small for all simulations with respect to their ensemble means.

It is obvious that the SOL simulation (Fig. 1b) has TDT amplitudes similar to the REF amplitudes (Fig. 1a). Usually, SOL amplitudes are slightly smaller, but locally they can also be larger than in REF. It has been demonstrated by Lilienthal et al. (2018) that this feature is owing to destructive phase relations between the propagating TDTs excited by solar heating and nonlinear tidal interactions, respectively.

The nonlinearly excited TDT (Fig. 1c) maximizes in the Northern (winter) Hemisphere. Amplitudes are smaller than in REF by a factor of 2-3. The nonlinear TDT has been modeled earlier (e.g., Smith and Ortland, 2001; Huang et al., 2007), but their seasonal cycle was considerably different from our model results (see also Supplement), i.e., the earlier simulations led to maxima at low latitudes (Smith and Ortland, 2001) and during equinoxes (Huang et al., 2007).

On average, the amplitudes of the GWF simulation (Fig. 1d) are smaller than those of the NLIN simulation (Fig. 1c). However, in other seasons and at certain altitudes it can be different (see Fig. S2). When the GWF amplitudes maximize, they reach a similar magnitude to those obtained by Miyahara and Forbes (1991). 

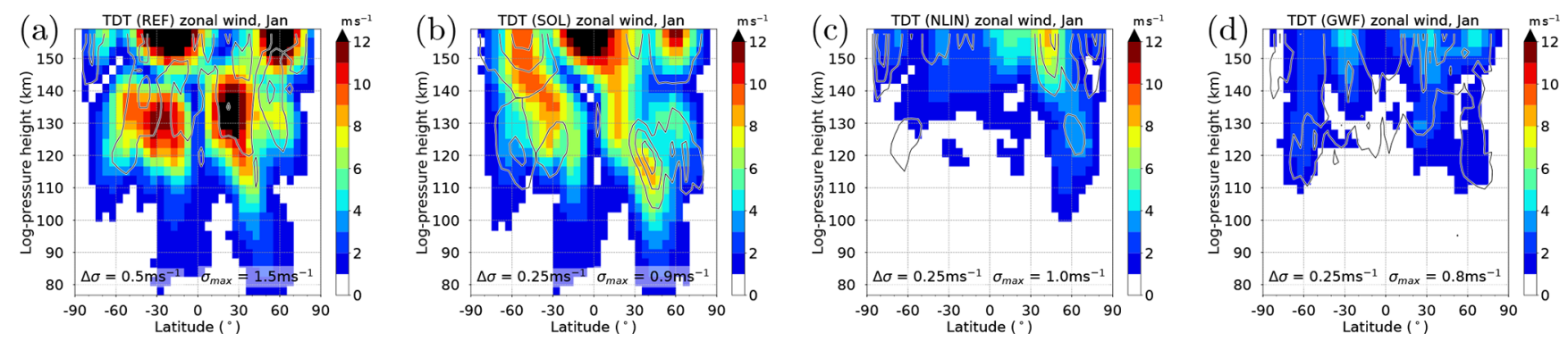

Figure 1. Latitude-altitude distribution of January mean TDT amplitudes owing to different forcing mechanisms. (a) REF, (b) SOL, (c) NLIN, and (d) GWF. Contour lines denote standard deviations $\sigma$ starting at $\sigma_{0}=\Delta \sigma$ in steps of $\Delta \sigma$ and with a maximum of $\sigma_{\text {max }}$ as indicated in each panel.

\subsection{Impact of different forcing mechanisms on tidal amplitudes and background}

In this section we analyze the effect of each different forcing on the TDT as well as the background atmosphere. Therefore, the SOL, NLIN, and GWF simulations now serve as a reference for the TDT amplitudes and the respective background circulation. In each of these simulations, we enhance the active forcing mechanism (tendency term) in each time step and for each latitude/altitude by $5 \%$ of the respective original value, i.e., the solar forcing is enhanced in SOL, the nonlinear forcing is enhanced in NLIN, and the GW forcing is enhanced in GWF. These respective enhanced simulations are called SOL5, NL5, and GW5.

Figure 2 shows the observed amplitude change of the respective terdiurnal forcing terms for January (panels a-d) and April (panels e-h) in the thermal (panels a, b, e, f) and dynamical (panels c, d, g, h) parameters (for July and October conditions see Fig. S3). Thereby, the data at each grid point are normalized by their value in the respective reference simulation. For example, the terdiurnal nonlinear forcing of NL5 is normalized by the terdiurnal nonlinear forcing of the NLIN simulation. The solar forcing term of the SOL5 simulation is not shown in Fig. 2 because the effect is nearly linear, i.e., the strength of the enhancement almost shows the expected value of $+5 \%$ with a maximum deviation between $+4.6 \%$ and $+5.3 \%$ during solstices. Figure 2 demonstrates that the observed nonlinear (NL5) and GW tendency terms (GW5) can strongly deviate from $+5 \%$ compared with NLIN and GWF, respectively. The nonlinear forcing terms (temperature advection and zonal wind acceleration; Fig. 2a, c, e, g) show a change in the terdiurnal forcing between roughly $-8 \%$ and $+22 \%$. However, as indicated by the shaded areas, these are rather exceptional cases, and usually the forcing enhancement varies between $4.5 \%$ and $5.5 \%$. The GW forcing terms are more extreme, ranging from $-92 \%$ to $+500 \%$ in the heating component (Fig. 2b, f) and from $-93 \%$ to almost $+1800 \%$ in the zonal wind drag component (Fig. 2d, h). The shading for the enhanced GW forcing covers a range between
0 and $10 \%$, but shaded areas are rather small, indicating that these large numbers are not only outliers.

A possible reason for these large discrepancies are feedback mechanisms within the model. It is widely known (e.g., Lindzen, 1981; Holton, 1982) that GWs strongly influence the background circulation, being responsible for the wind reversal in the mesosphere due to wave breaking and momentum deposition. Therefore, a change in the terdiurnal component of GW drag may also influence the background circulation, leading to altered propagation condition for tides, which again affects the terdiurnal component of GW drag. Such a mechanism is very difficult to control within a nonlinear model. Before we go into detail regarding the analysis of the background circulation, we first have a look at the amplitude of the TDT due to the increased forcing.

Figure 3 shows the January mean latitude-altitude distribution of TDT zonal wind (panels a, c) and temperature (panels b, d) amplitudes of the NL5 (panels a, b) and GW5 (panels c, d) ensemble simulations. Different seasons are shown in the Supplement (Fig. S4). The vertical profiles to the right of each latitude-altitude distribution in Fig. 3 show the monthly mean horizontal mean relative amplitude changes $\Delta A$ for NL5 and GW5 where

$\Delta A_{\mathrm{NL} 5}=\left(A_{\mathrm{NL} 5}-A_{\mathrm{NLIN}}\right) / A_{\mathrm{NLIN}} \cdot 100$

and

$\Delta A_{\mathrm{GW} 5}=\left(A_{\mathrm{GW} 5}-A_{\mathrm{GWF}}\right) / A_{\mathrm{GWF}} \cdot 100$.

The NL5 simulation (Fig. 3a) looks similar to NLIN (Fig. 1c), because the enhancement of $5 \%$ is mostly too small to be visible in the chosen color scheme. The variability between the different seasons (Fig. 3a, profiles) is small for all altitudes, and the zonal wind amplitudes in NL5 are approximately $4 \%$ to $6 \%$ larger than in NLIN. The temperature amplitude (Fig. 3b) shows a similar behavior below $130 \mathrm{~km}$, but above this altitude the horizontal mean TDT amplitudes roughly vary between $0 \%$ and $+8 \%$ compared with the original forcing. During April (light blue line), the amplitude even slightly decreases near $150 \mathrm{~km}$, i.e., the change is negative. 

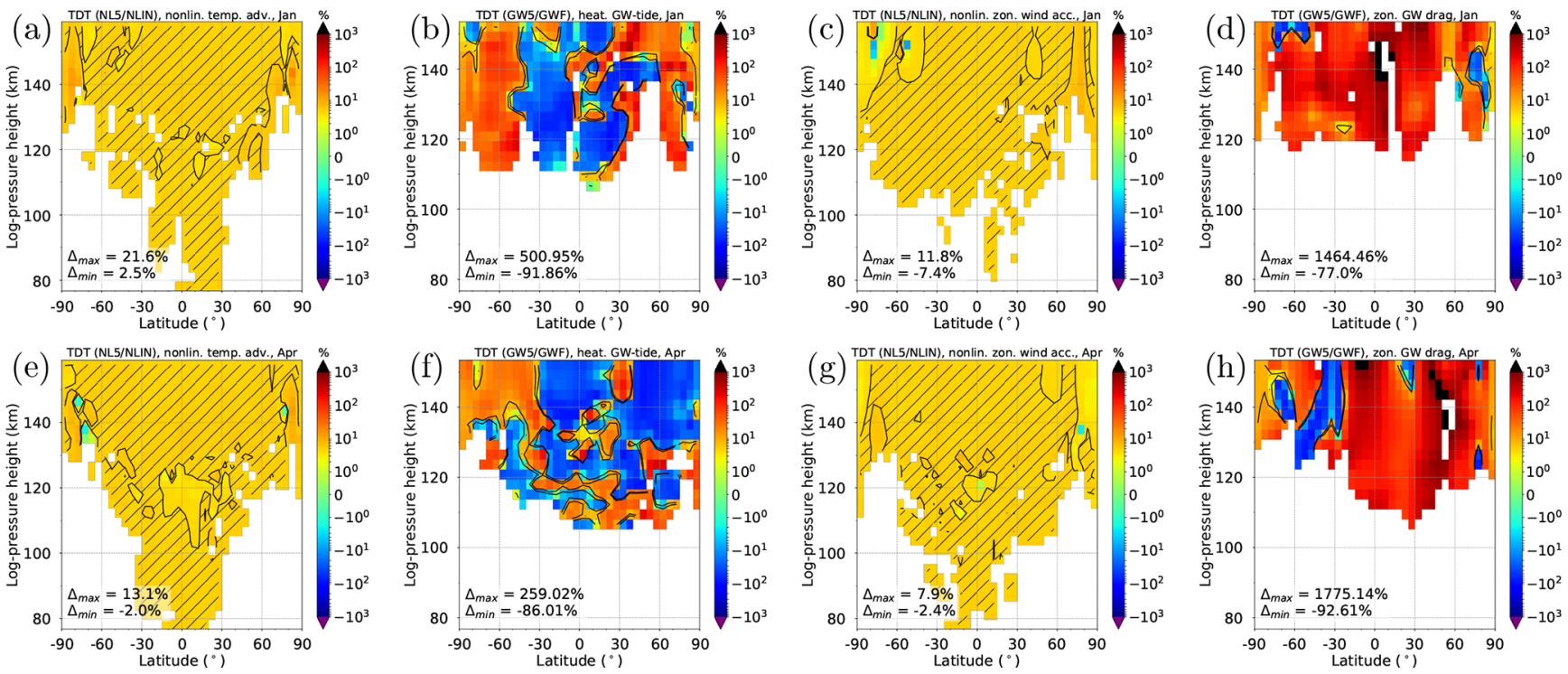

Figure 2. Relative change of terdiurnal forcing terms for an implemented increase of $5 \%$ for January (a-d) and April (e-h). From left to right: nonlinear temperature advection (a, e), heating due to GW-tide interactions (b, f), nonlinear zonal wind acceleration (c, g), and zonal drag due to GW-tide interactions (d, h). Red (blue) colors refer to a larger forcing in NL5 and GW5 (NLIN and GWF). Hatched areas highlight the values $4.5 \% \leq(\mathrm{NL} 5 / \mathrm{NLIN}-1) \cdot 100 \leq 5.5 \%$ and $0 \% \leq(\mathrm{GW} 5 / \mathrm{GWF}-1) \cdot 100 \leq 10 \%$, respectively. Blank areas denote that the respective forcing in NLIN is smaller than $1 \mathrm{~K}\left(2 \mathrm{~m} \mathrm{~s}^{-1}\right)$, and the respective forcing in GWF is smaller than $\left.1 \mathrm{~K}^{(10 \mathrm{~m} \mathrm{~s}}{ }^{-1}\right)$.
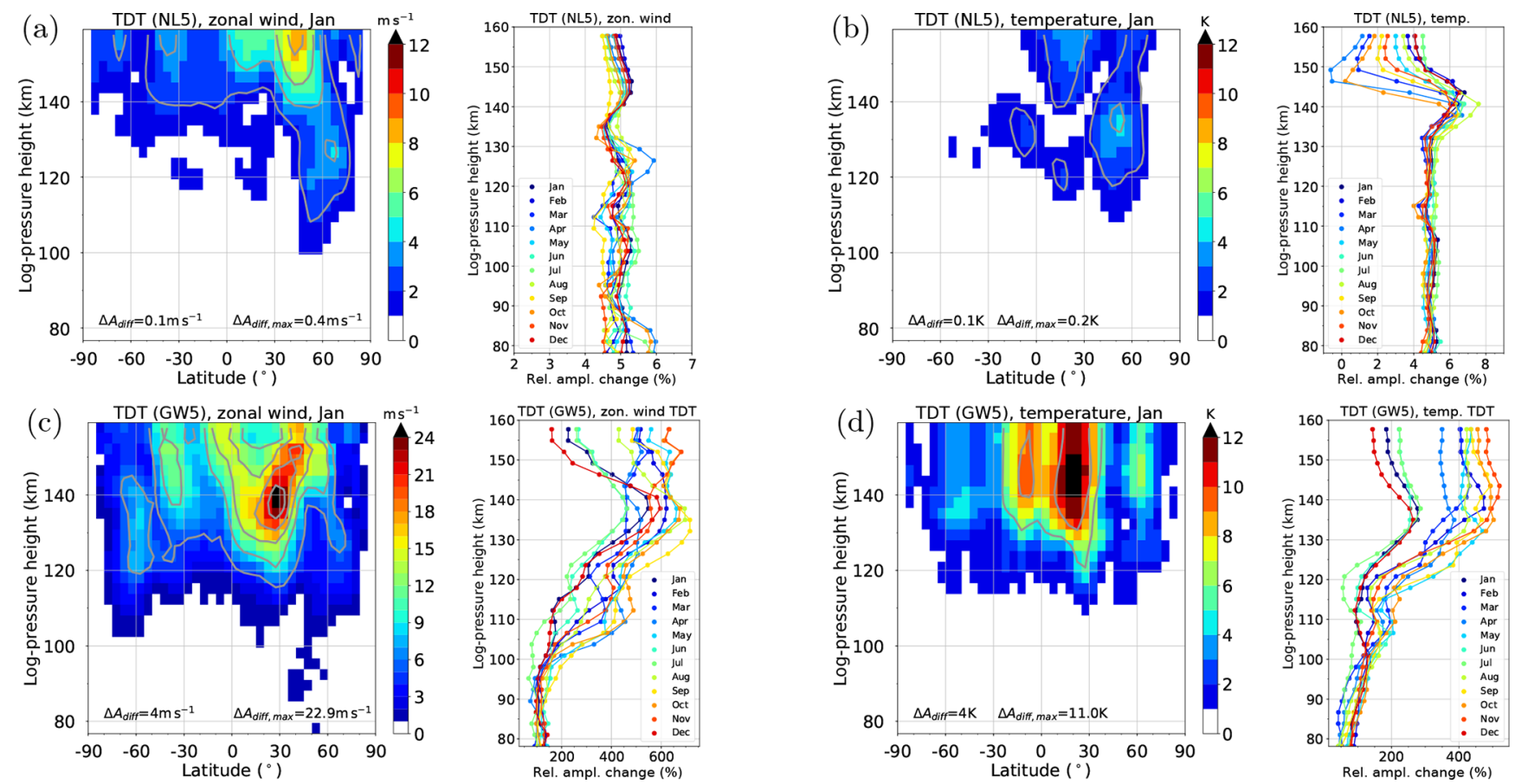

Figure 3. Color plots: latitude-altitude distribution of TDT zonal wind (a, c) and TDT temperature amplitudes (b, d) in the NL5 (a, b) and GW5 (c, d) simulations for the January ensemble mean. Contour lines denote differences to the NLIN (a, b) and GWF (c, d) ensemble simulations. Vertical profiles show the monthly mean horizontal mean TDT amplitudes, displayed as a relative change compared with NLIN (a, b) and GWF (c, d), respectively. Different colors refer to different months (see legend). Note that the scales are different. 

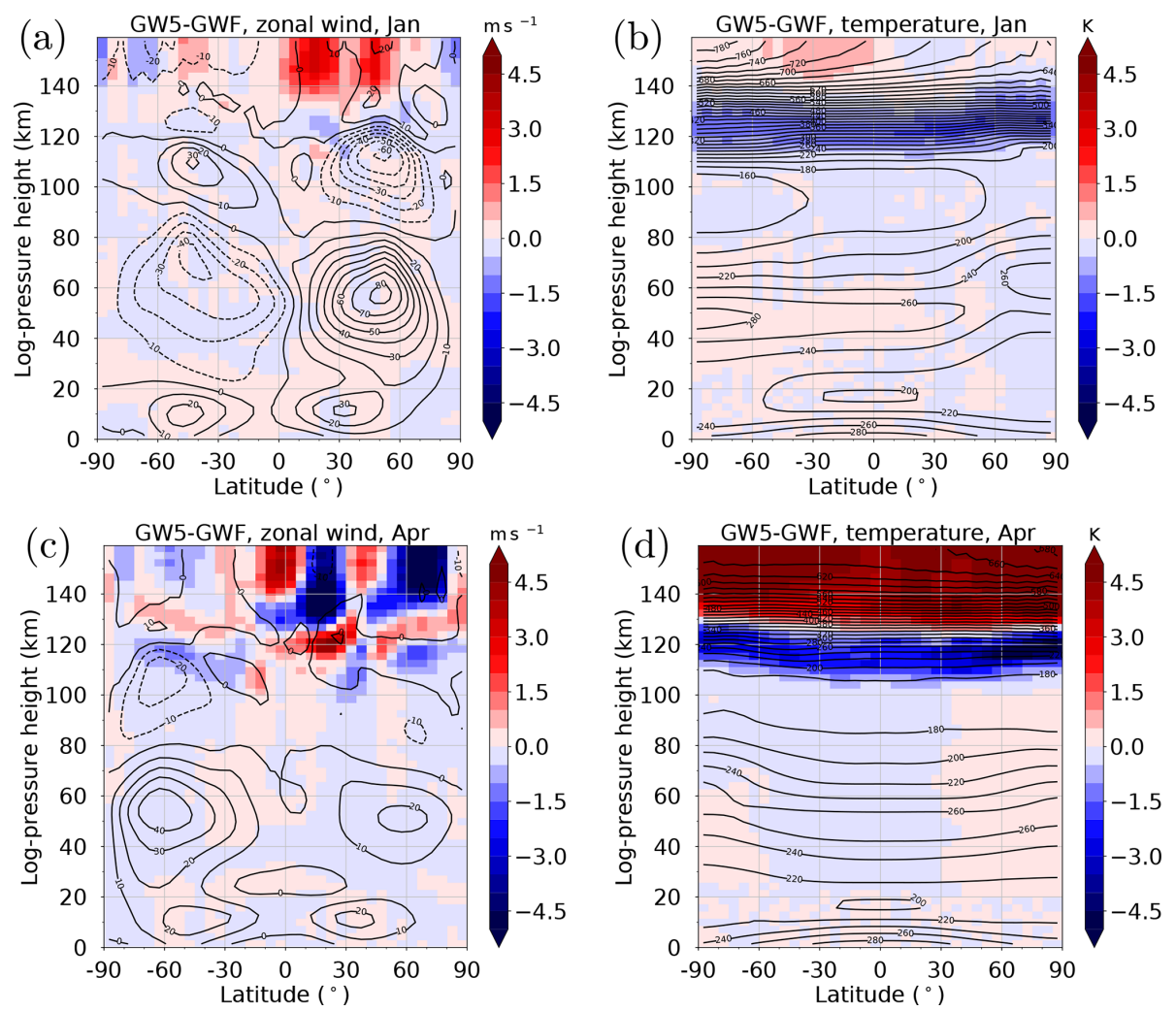

Figure 4. Contour lines: latitude-altitude distribution of zonal mean zonal wind (a, c) and zonal mean temperature (b, d) in the GW5 ensemble simulation for January $(\mathbf{a}, \mathbf{b})$ and April $(\mathbf{c}, \mathbf{d})$. Color shading denotes differences compared with GWF.

The zonal wind TDT amplitudes due to a $5 \%$ increased GW forcing (Fig. 3c) are drastically increased in comparison to the GWF amplitudes in Fig. 1d. This is mainly an effect of the increased GW forcing terms. They do not only influence the zonal wind amplitude (Fig. 3c) but also the temperature tide (Fig. 3d). Below $100 \mathrm{~km}$, the amplitudes are approximately doubled $(+100 \%)$. This factor further increases up to an altitude of $140 \mathrm{~km}$, reaching a maximum increase of more than $600 \%$ (zonal wind) and about $500 \%$ (temperature), respectively. These maxima are found in August/September (zonal wind) and October/November (temperature). The change in amplitude is enormous, considering that the GW forcing was only increased by $5 \%$ in each time step. However, the overall change in the forcing locally amounts to $+500 \%$ (in the heating due to GWs, see Fig. 2b) and to almost $+1800 \%$ (in the zonal GW drag, see Fig. 2h), which is possibly due to feedback mechanisms within the model that also influence the background conditions and GW propagation conditions. Therefore, the dramatic increase in TDT amplitude can be partly explained by the strongly enhanced GW forcing. Furthermore, the TDT amplitude changes are considerably strong above $100 \mathrm{~km}$, which coincides with the fact that the terdiurnal zonal GW drag maximizes in the thermosphere (Fig. 2).
The differences of the zonal mean zonal wind and zonal mean temperature are shown in Fig. 4, each for January and April conditions (for July and October conditions see Fig. S5). We only show the differences between GW5 and GWF, and not between NL5 and NLIN because the latter differences are small. It can be seen in Fig. 4 that the terdiurnal GW forcing only affects the thermosphere. Below $130 \mathrm{~km}$, the thermosphere experiences a cooling, whereas above that height there is a warming, in particular during April (Fig. 4b, d). The zonal wind during January (Fig. 4a) is mainly accelerated in the eastward direction, with a maximum at low and middle latitudes of the Northern Hemisphere (NH) above $130 \mathrm{~km}$. As a result, the westerly winds in that region are slightly enhanced by about $+3 \mathrm{~m} \mathrm{~s}^{-1}$. During April, the zonal wind in the thermosphere is generally small. The enhanced GW forcing leads to an alternating pattern of eastward and westward directed acceleration with a magnitude of about $\pm 5 \mathrm{~m} \mathrm{~s}^{-1}$, again with maxima in the NH. The magnitude of the cooling/warming of the thermosphere strongly depends on the strength of the terdiurnal GW forcing, i.e., it becomes stronger for stronger enhancements (not shown here).

Figure 5 shows the behavior of TDT amplitudes depending on different factors of forcing enhancements where a factor of 1.05 refers to an increase of $5 \%$. Figure $5 \mathrm{a}$ and $\mathrm{b}$ refer to an increase of the terdiurnal nonlinear forcing in steps of 
(a)

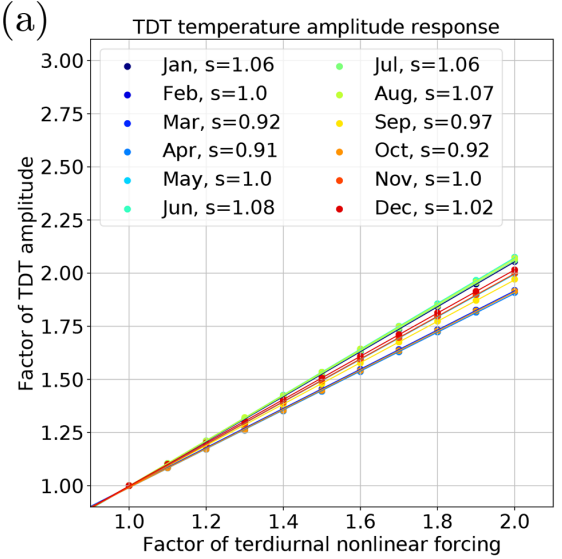

(c)

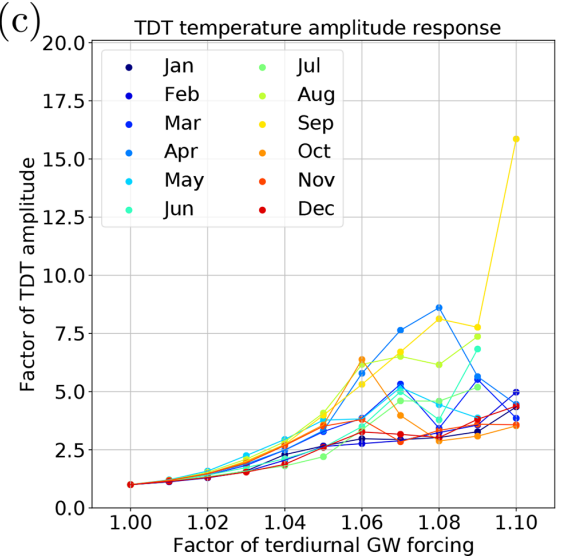

(b)

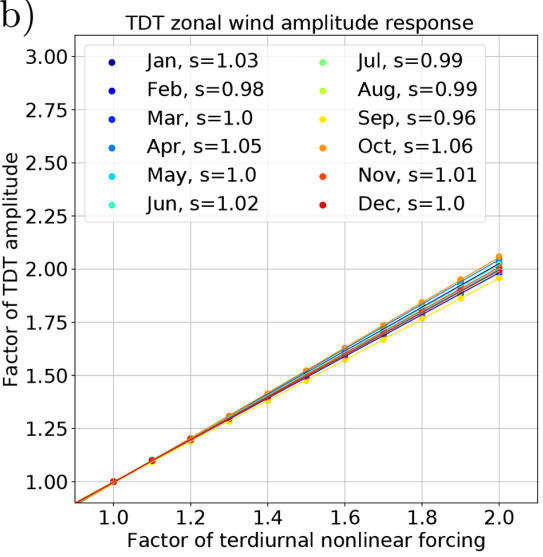

(d)

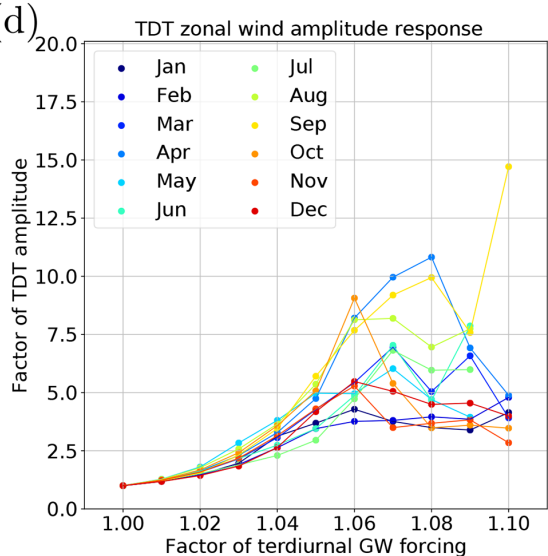

Figure 5. Normalized, horizontal mean vertical mean (80-160 km height range) TDT amplitudes for temperature (a, c) and zonal wind (b, d) according to an increased terdiurnal forcing in $\operatorname{NLIN}_{2000}(\mathbf{a}, \mathbf{b})$ and $\mathrm{GWF}_{2000}(\mathbf{c}, \mathbf{d})$. Different colors refer to different months. Dots denote specific simulations. For the enhancement of the nonlinear forcing $(\mathbf{a}, \mathbf{b})$, a linear fit is added for each month (corresponding slope $s$ : see legend).

$10 \%$ enhancement, and Fig. $5 \mathrm{c}$ and d refer to an increase of the terdiurnal GW forcing in steps of $1 \%$. The amplitude response is shown for the temperature (Fig. 5a, c) and the zonal wind component (Fig. 5b, d). The different colors refer to different months of the year 2000 and the relative amplitude change is globally averaged (horizontal mean vertical mean) for a height range of 80 to $160 \mathrm{~km}$.

For the increased nonlinear forcing (Fig. 5a, b), a linear fit is added where each fit has a squared correlation coefficient $R^{2}>0.99$ and the respective slopes $(s)$ are given in the legend. They are close to one, suggesting that the amplitude is directly correlated with the factor of increase in the nonlinear forcing. However, this does not mean that the total observed amplitude in the REF simulation is increased by the same factor. The increase in amplitude only refers to the pure nonlinear part of the TDT. Due to the fact that the nonlinear TDT is much weaker than the solar TDT, its overall impact is rather small.

The dependence of TDT amplitudes on the GW forcing (Fig. 5c, d) are irregular for implemented enhancements larger than $5 \%$. For an increase of $10 \%$, the model becomes instable for the months June, July, and August as indicated by the missing data points. This is certainly related to the influence of GWs on the zonal mean circulation, as shown exemplary for January and April in Fig. 4, and for all months in Fig. 6. This figure is similar to Fig. 5, but instead of amplitudes we show the global mean $(80$ to $160 \mathrm{~km})$ absolute value of zonal mean differences to NLIN or GWF of the year 2000 , respectively. Instead of the slopes, we show the correlation coefficients for the linear fits in the legend of Fig. 6a and $b$. These are close to one for most of the months, except for June to August (for zonal mean temperature) and for June to September (for zonal mean zonal wind). However, the overall impact of nonlinear forcing mechanisms on the background circulation is small as global mean differences amount to less than $0.5 \mathrm{~K}$ and $0.5 \mathrm{~m} \mathrm{~s}^{-1}$, respectively.

Again, the response is much more relevant, when the GW forcing is increased (Fig. 6c, d). The temperature reveals an exponential-like increase in the absolute temperature change where an increase of $10 \%$ can change the zonal mean tem- 

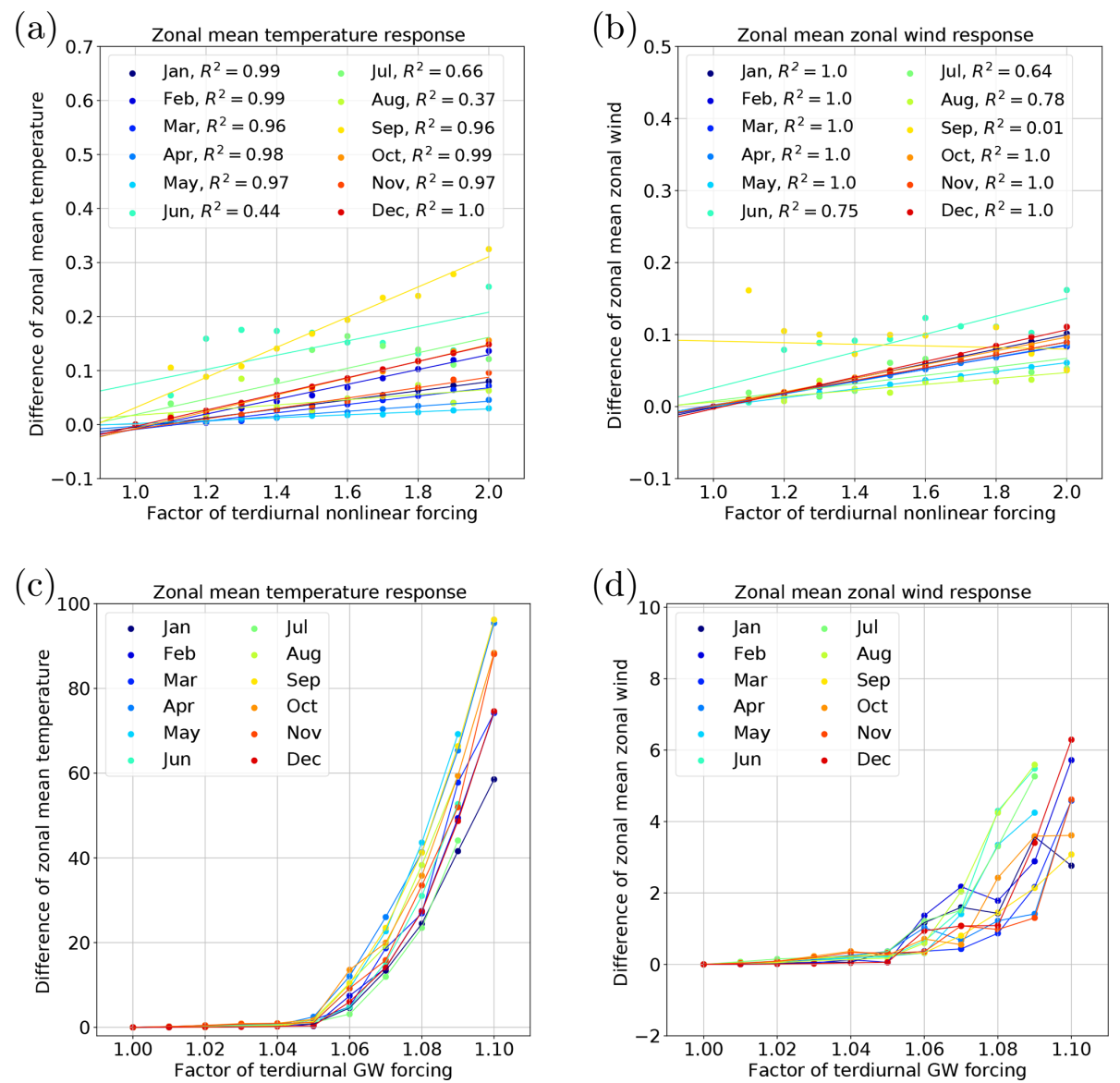

Figure 6. Horizontal mean vertical mean (80-160 km height range) absolute change of zonal mean temperature (a, c) and zonal wind (b, d) according to an increased terdiurnal forcing in $\operatorname{NLIN}_{2000}(\mathbf{a}, \mathbf{b})$ and $\mathrm{GWF}_{2000}(\mathbf{c}, \mathbf{d})$. The factor of the increased nonlinear $(\mathbf{a}, \mathbf{b})$ and GW forcing $(\mathbf{c}, \mathbf{d})$ is indicated on the abscissa. Units of the ordinate are meters per second $\left(\mathrm{m} \mathrm{s}^{-1}\right)$ and Kelvin (K), respectively. For the enhancement of the nonlinear forcing $(\mathbf{a}, \mathbf{b})$, a linear fit is added for each month (corresponding correlation coefficients $R^{2}$ : see legend).

perature above $80 \mathrm{~km}$ by more than $50 \mathrm{~K}$ on a global average and the zonal mean zonal wind by about 2 to $6 \mathrm{~ms}^{-1}$. The maximum temperature change is found in the thermosphere as shown in Fig. 4. To give an example, an increase of the GW forcing by $10 \%$ in January leads to a temperature decrease of about $10 \mathrm{~K}$ in the mesosphere (about $110 \mathrm{~km}$ altitude). The patterns of the differences are in this case similar to those shown in Fig. 4. In the thermosphere, the temperature is drastically increased by up to $140 \mathrm{~K}$ near the upper boundary of the model.

\section{Conclusions}

Based on the experiments by Lilienthal et al. (2018), we performed extended simulations of the terdiurnal solar tide using a mechanistic global circulation model. Besides the primary forcing, which is the absorption of solar radiation in the lower atmosphere (Chapman and Lindzen, 1970; Andrews et al., 1987), further possible sources of atmospheric tides are nonlinear tidal interactions (e.g., Glass and Fellous, 1975; Teit- elbaum et al., 1989) and gravity wave-tide interactions (e.g., Miyahara and Forbes, 1991; Ribstein and Achatz, 2016).

In order to separate the forcing mechanisms, we performed simulations in which we kept only one of these forcings and removed the other sources. As a result, these simulations allowed us to show the amplitudes of the TDT based on each excitation mechanism, separately, and we found that the global structure of the simulated TDT (REF simulation) is in good accordance with measurements in the MLT. Furthermore, the pure solar forcing (SOL simulation) explains most of the TDT global structure. This, in combination with the small TDT amplitudes of NLIN and GWF, indicates that the direct solar heating is the most important excitation mechanism of the TDT. Nonlinear tidal interactions only play a role during local winter at midlatitudes above $100 \mathrm{~km}$ and during equinoxes above $140 \mathrm{~km}$. GW-tide interactions mainly appear in the thermosphere with maxima during $\mathrm{NH}$ summer and during equinoxes above the Equator.

The influence of the nonlinear tidal and GW-tide interactions on TDT amplitudes and on the zonal mean circulation 
was investigated based on a sensitivity study with enhanced terdiurnal forcing terms. Each simulation represented a certain factor of increase and we focused on the $5 \%$ increase simulation which was the best compromise between significant changes in the atmosphere and the numerical stability of the simulations. Our main results are as follows:

- There is a direct and linear relationship between the nonlinear tidal forcing and the TDT amplitudes, but its influence on the zonal mean circulation is small.

- The influence of GW-tide interactions is more irregular with respect to the TDT amplitude, indicating that GWs can play an important role for TDT forcing when the conditions for GW-tide interactions are favorable, especially in the thermosphere (e.g., Yiğit et al., 2008). Lilienthal et al. (2018) have shown that terdiurnal zonal GW drag is large in the thermosphere and this may also cause the large TDT amplitudes.

- There is an exponential-like relationship between the strength of terdiurnal GW-tide interactions and the zonal mean circulation in the thermosphere, which is cooled below $130 \mathrm{~km}$ and heated above. This is more pronounced in April than in January. Zonal wind in the thermosphere is slightly increased in January and has a more complex pattern in April. In all seasons, the zonal mean zonal winds can be reversed in the thermosphere by slightly modified terdiurnal GW-tide interactions.

Note that an artificial enhancement of the terdiurnal GW drag releases more energy into the system, i.e., GW amplitudes are larger causing GWs to reach higher altitudes. In the thermosphere, they release their energy due to wave breaking and can thereby strongly influence the dynamics in this region.

To conclude, modifications of terdiurnal forcing mechanisms do not only have an effect on TDT amplitudes but they may also influence the background circulation, especially with respect to the terdiurnal GW drag. As tidal forcing in a real atmosphere is not as regular as in our model, such interactions may play an important role for the vertical coupling of the atmosphere. Our simulations also demonstrate the importance of GW-tide interactions and their consideration in global circulation models.

Code availability. The MUAM model code can be obtained from the corresponding author upon request.

Supplement. The supplement related to this article is available online at: https://doi.org/10.5194/angeo-37-943-2019-supplement.

Author contributions. FL designed and performed the MUAM model runs. FL and CJ wrote the first version of the text and discussed the results.
Competing interests. Christoph Jacobi is one of the editors in chief of Annales Geophysicae.

Special issue statement. This article is part of the special issue "Vertical coupling in the atmosphere-ionosphere system". It is a result of the 7th Vertical coupling workshop, Potsdam, Germany, 2-6 July 2018.

Acknowledgements. SPARC global ozone fields are provided by William J. Randel (NCAR) at ftp://sparc-ftp1.ceda.ac.uk/sparc/ref_ clim/randel/o3data/ (last access: 13 August 2018). Mauna Loa carbon dioxide mixing ratios are provided by NOAA at $\mathrm{ftp}: / /$ aftp.cmdl.noaa.gov/products/trends/co2/co2_mm_mlo.txt (last access: 8 October 2019). ERA-Interim data are provided by ECMWF at https://apps.ecmwf.int/datasets/data/interim-full-moda/levtype= pl/ (last access: 8 October 2019).

Financial support. This research has been supported by the Deutsche Forschungsgemeinschaft (grant no. JA 836/30-1).

Review statement. This paper was edited by Petra Koucka Knizova and reviewed by two anonymous referees.

\section{References}

Akmaev, R.: Seasonal variations of the terdiurnal tide in the mesosphere and lower thermosphere: a model study, Geophys. Res. Lett., 28, 3817-3820, https://doi.org/10.1029/2001GL013002, 2001.

Andrews, D. G., Holton, J. R., and Leovy, C. B.: Middle Atmosphere Dynamics, Academic Press Inc., Ltd., London, 1987.

Baumgarten, K., Gerding, M., Baumgarten, G., and Lübken, F.-J.: Temporal variability of tidal and gravity waves during a record long 10-day continuous lidar sounding, Atmos. Chem. Phys., 18, 371-384, https://doi.org/10.5194/acp-18-371-2018, 2018.

Beldon, C., Muller, H., and Mitchell, N.: The 8-hour tide in the mesosphere and lower thermosphere over the UK, 1988-2004, J. Atmos. Sol.-Terr. Phy., 68, 655-668, https://doi.org/10.1016/j.jastp.2005.10.004, 2006.

Cevolani, G. and Bonelli, P.: Tidal activity in the middle atmosphere, Nuovo Cimento C, 8, 461-490, https://doi.org/10.1007/BF02582675, 1985.

Chapman, S. and Lindzen, R. S.: D. Reidel Publishing Company, Dordrecht, the Netherlands, 1970.

Danielson, G. C. and Lanczos, C.: Some improvements in practical Fourier analysis and their application to $\mathrm{x}$-ray scattering from liquids, J. Frankl. Inst., 233, 365-380, https://doi.org/10.1016/S0016-0032(42)90767-1, 1942.

Dee, D. P., Uppala, S. M., Simmons, A. J., Berrisford, P., Poli, P., Kobayashi, S., Andrae, U., Balmaseda, M. A., Balsamo, G., Bauer, P., Bechtold, P., Beljaars, A. C. M., van de Berg, L., Bidlot, J., Bormann, N., Delsol, C., Dragani, R., Fuentes, M., Geer, A. J., Haimberger, L., Healy, S. B., Hersbach, H., Hólm, E. V., 
Isaksen, L., Kållberg, P., Köhler, M., Matricardi, M., McNally, A. P., Monge-Sanz, B. M., Morcrette, J.-J., Park, B.-K., Peubey, C., de Rosnay, P., Tavolato, C., Thépaut, J.-N., and Vitart, F.: The ERA-Interim reanalysis: configuration and performance of the data assimilation system, Q. J. Roy. Meteor. Soc., 137, 553-597, https://doi.org/10.1002/qj.828, 2011.

Du, J. and Ward, W. E.: Terdiurnal tide in the extended Canadian Middle Atmospheric Model (CMAM), J. Geophys. Res., 115, D24106, https://doi.org/10.1029/2010JD014479, 2010.

Eckermann, S. D. and Marks, C. J.: An idealized ray model of gravity wave-tidal interactions, J. Geophys. Res.-Atmos., 101, 21195-21212, https://doi.org/10.1029/96JD01660, 1996.

Eckermann, S. D., Rajopadhyaya, D. K., and Vincent, R. A.: Intraseasonal wind variability in the equatorial mesosphere and lower thermosphere: long-term observations from the central Pacific, J. Atmos. Sol.-Terr. Phy., 59, 603-627, https://doi.org/10.1016/S1364-6826(96)00143-5, 1997.

ERA-Interim: Monthly mean temperature and geopotential fields on pressure levels 1979-date; Eurpoean Reanalysis Interim, available at: http://apps.ecmwf.int/datasets/data/interim-full-moda/ levtype $=$ pl, last access: 13 August 2018.

Forbes, J. M.: Tidal and Planetary Waves, 67-87, American Geophysical Union (AGU), https://doi.org/10.1029/GM087p0067, 1995.

Fritts, D. C. and Alexander, M. J.: Gravity wave dynamics and effects in the middle atmosphere, Rev. Geophys., 41, 1003, https://doi.org/10.1029/2001RG000106, 2003.

Fröhlich, K., Pogoreltsev, A., and Jacobi, C.: Numerical simulation of tides, Rossby and Kelvin waves with the COMMA-LIM model, Adv. Space Res., 32, 863-868, https://doi.org/10.1016/S0273-1177(03)00416-2, 2003.

Glass, M. and Fellous, J. L.: The eight-hour (terdiurnal) component of atmospheric tides, Space Res., 15, 191-197, 1975.

Guharay, A., Batista, P. P., Clemesha, B. R., Sarkhel, S., and Buriti, R. A.: On the variability of the terdiurnal tide over a Brazilian equatorial station using meteor radar observations, J. Atmos. Sol.-Terr. Phy., 104, 87-95, https://doi.org/10.1016/j.jastp.2013.08.021, 2013.

Hoffmann, P., Jacobi, C., and Borries, C.: Possible planetary wave coupling between the stratosphere and ionosphere by gravity wave modulation, J. Atmos. Sol.-Terr. Phy., 75-76, 71-80, https://doi.org/10.1016/j.jastp.2011.07.008, 2012.

Holton, J. R.: The Role of Gravity Wave Induced Drag and Diffusion in the Momentum Budget of the Mesosphere, J. Atmos. Sci., 39, 791-799, https://doi.org/10.1175/15200469(1982)039<0791:TROGWI>2.0.CO;2, 1982.

Huang, C., Zhang, S., and Yi, F.: A numerical study on amplitude characteristics of the terdiurnal tide excited by nonlinear interaction between the diurnal and semidiurnal tides, Earth Planets Space, 59, 183-191, https://doi.org/10.1186/BF03353094, 2007.

Jacobi, C.: 6 year mean prevailing winds and tides measured by VHF meteor radar over Collm $\left(51.3^{\circ} \mathrm{N}\right.$, 13.0 $0^{\circ}$ ), J. Atmos. Sol.-Terr. Phy., 78-79, 8-18, https://doi.org/10.1016/j.jastp.2011.04.010, 2012.

Jacobi, Ch. and Fytterer, T.: The 8-h tide in the mesosphere and lower thermosphere over Collm $\left(51.3^{\circ} \mathrm{N} ; 13.0^{\circ} \mathrm{E}\right), 2004-2011$, Adv. Radio Sci., 10, 265-270, https://doi.org/10.5194/ars-10265-2012, 2012.
Jacobi, C., Fröhlich, K., and Pogoreltsev, A.: Quasi twoday-wave modulation of gravity wave flux and consequences for the planetary wave propagation in a simple circulation model, J. Atmos. Sol.-Terr. Phy., 68, 283-292, https://doi.org/10.1016/j.jastp.2005.01.017, 2006.

Jakobs, H. J., Bischof, M., Ebel, A., and Speth, P.: Simulation of gravity wave effects under solstice conditions using a 3-D circulation model of the middle atmosphere, J. Atmos. Sol.-Terr. Phy., 48, 1203-1223, https://doi.org/10.1016/0021-9169(86)90040-1, 1986.

Lilienthal, F., Jacobi, C., Schmidt, T., de la Torre, A., and Alexander, P.: On the influence of zonal gravity wave distributions on the Southern Hemisphere winter circulation, Ann. Geophys., 35, 785-798, https://doi.org/10.5194/angeo-35-785-2017, 2017.

Lilienthal, F., Jacobi, C., and Geißler, C.: Forcing mechanisms of the terdiurnal tide, Atmos. Chem. Phys., 18, 15725-15742, https://doi.org/10.5194/acp-18-15725-2018, 2018.

Lindzen, R. S.: Turbulence and stress owing to gravity wave and tidal breakdown, J. Geophys. Res.-Oceans, 86, 9707-9714, https://doi.org/10.1029/JC086iC10p09707, 1981.

Meyer, C. K.: Gravity wave interactions with mesospheric planetary waves: A mechanism for penetration into the thermosphereionosphere system, J. Geophys. Res.-Space, 104, 28181-28196, https://doi.org/10.1029/1999JA900346, 1999.

Miyahara, S. and Forbes, J. M.: Interactions between Gravity Waves and the Diurnal Tide in the Mesosphere and Lower Thermosphere, J. Meteorol. Soc. Jpn. Ser. II, 69, 523-531, https://doi.org/10.2151/jmsj1965.69.5_523, 1991.

Moudden, Y. and Forbes, J. M.: A decade-long climatology of terdiurnal tides using TIMED/SABER observations, J. Geophys. Res.-Space, 118, 4534-4550, https://doi.org/10.1002/jgra.50273, 2013.

Pancheva, D., Mukhtarov, P., and Smith, A. K.: Climatology of the migrating terdiurnal tide (TW3) in SABER/ TIMED temperatures, J. Geophys. Res.-Space, 118, 1755-1767, https://doi.org/10.1002/jgra.50207, 2013.

Pokhotelov, D., Becker, E., Stober, G., and Chau, J. L.: Seasonal variability of atmospheric tides in the mesosphere and lower thermosphere: meteor radar data and simulations, Ann. Geophys., 36, 825-830, https://doi.org/10.5194/angeo-36-825-2018, 2018.

Reddi, C. R., Rajeev, K., and Geetha, R.: Tidal winds in the radio-meteor region over Trivandrum $\left(8.5^{\circ} \mathrm{N}, 77^{\circ} \mathrm{E}\right)$, J. Atmos. Terr. Phys., 55, 1219-1231, https://doi.org/10.1016/00219169(93)90049-5, 1993.

Ribstein, B. and Achatz, U.: The interaction between gravity waves and solar tides in a linear tidal model with a 4-D ray-tracing gravity-wave parameterization, J. Geophys. Res.-Space, 121, 8936-8950, https://doi.org/10.1002/2016JA022478, 2016.

Senf, F. and Achatz, U.: On the impact of middle-atmosphere thermal tides on the propagation and dissipation of gravity waves, J. Geophys. Res.-Atmos., 116, D24110, https://doi.org/10.1029/2011JD015794, 2011.

Smith, A. and Ortland, D.: Modeling and Analysis of the Structure and Generation of the Terdiurnal Tide, J. Atmos. Sci., 58, 3116-3134, https://doi.org/10.1175/15200469(2001)058<3116:MAAOTS>2.0.CO;2, 2001.

Smith, A. K.: Structure of the terdiurnal tide at $95 \mathrm{~km}$, Geophys. Res, Lett., 27, 177-180, https://doi.org/10.1029/1999GL010843, 2000. 
Smith, A. K.: Global Dynamics of the MLT, Surv. Geophys., 33, 1177-1230, https://doi.org/10.1007/s10712-012-9196-9, 2012.

Strobel, D. F.: Parameterization of the atmospheric heating rate from 15 to $120 \mathrm{~km}$ due to $\mathrm{O}_{2}$ and $\mathrm{O}_{3}$ absorption of solar radiation, J. Geophys. Res.-Oceans, 83, 6225-6230, https://doi.org/10.1029/JC083iC12p06225, 1978.

Teitelbaum, H. and Vial, F.: On tidal variability induced by nonlinear interaction with planetary waves, J. Geophys. Res.-Space, 96, 14169-14178, https://doi.org/10.1029/91JA01019, 1991.

Teitelbaum, H., Vial, F., Manson, A., Giraldez, R., and Massebeuf, M.: Non-linear interaction between the diurnal and semidiurnal tides: terdiurnal and diurnal secondary waves, J. Atmos. Terr. Phys., 51, 627-634, https://doi.org/10.1016/00219169(89)90061-5, 1989.

Thayaparan, T.: The terdiurnal tide in the mesosphere and lower thermosphere over London, Canada $\left(43^{\circ} \mathrm{N}\right.$, $\left.81^{\circ} \mathrm{W}\right)$, J. Geophys. Res.-Atmos., 102, 21695-21708, https://doi.org/10.1029/97JD01839, 1997.

Yiğit, E. and Medvedev, A. S.: Internal wave coupling processes in Earthäs atmosphere, Adv. Space Res., 55, 983-1003, https://doi.org/10.1016/j.asr.2014.11.020, 2015.

Yiğit, E. and Medvedev, A. S.: Influence of parameterized small-scale gravity waves on the migrating diurnal tide in Earth's thermosphere, J. Geophys. Res.-Space, 122, 4846-4864, https://doi.org/10.1002/2017JA024089, 2017.
Yiğit, E., Aylward, A. D., and Medvedev, A. S.: Parameterization of the effects of vertically propagating gravity waves for thermosphere general circulation models: Sensitivity study, J. Geophys. Res., 113, D19106, https://doi.org/10.1029/2008JD010135, 2008.

Yiğit, E., Medvedev, A. S., Aylward, A. D., Hartogh, P., and Harris, M. J.: Modeling the effects of gravity wave momentum deposition on the general circulation above the turbopause, J. Geophys. Res.-Atmos., 114, D07101, https://doi.org/10.1029/2008JD011132, 2009.

Younger, P. T., Pancheva, D., Middleton, H. R., and Mitchell, N. J.: The 8-hour tide in the Arctic mesosphere and lower thermosphere, J. Geophys. Res.-Space, 107, 1420, https://doi.org/10.1029/2001JA005086, 2002.

Yue, J., Xu, J., Chang, L. C., Wu, Q., Liu, H.-L., Lu, X., and Russell, J.: Global structure and seasonal variability of the migrating terdiurnal tide in the mesosphere and lower thermosphere, J. Atmos. Sol.-Terr. Phy., 105-106, 191-198, https://doi.org/10.1016/j.jastp.2013.10.010, 2013. 